\title{
The Impact of Antibiotic Abuse: Health And Economic Burden
}

\author{
Khalid Ababneh* and Islam Emad Alkhazali \\ Ministry of Health, Jordan \\ *Corresponding author: Khalid Ababneh, Ministry of Health, Jordan
}

\begin{abstract}
ARTICLE INFO
Received: 槥 March 01, 2019

Published: March 19, 2019

Citation: Khalid Ababneh, Islam Emad Alkhazali. The Impact of Antibiotic Abuse: Health And Economic Burden. Biomed J Sci \& Tech Res 16(1)-2019. BJSTR. MS.ID.002802.

ABSTRACT

The present study reviewed the literature regarding using antibiotics from several points of view including their wide use, abuse, classification, health and economic impacts. The antibiotics have made a revolution in treating infectious diseases since their discoveries. The phenomenon of emerging resistance against antibiotics is considered a real health challenge that requires taking measures to rationally use antibiotics. Antimicrobial resistance is considered as an evolutionary process in relation to microbial genetics, and the term superbug has been used to describe the returning back of infections that were under control such as tuberculosis. Estimates have pointed out to large economic burden associated with antibiotic abuse.
\end{abstract}

Keywords: Antibiotics; Antibiotic Abuse; Bacteria; Antimicrobial Resistance; Health Impacts; Economic Burden

\section{Short Communication}

\section{An Overview of Antibiotics}

Antibiotic is an antimicrobial agent against bacteria and the most important form of an antibacterial agent for combating bacterial infections. Antibiotics are widely used to treat and prevent such infections (NHS, 2019). They can kill or inhibit the growth of bacteria. A limited number of antibiotics also have antiprotozoal activity [1]. The term antibiotic is broadly used to refer to any substance used against microbes, but in the usual medical usage, antibiotics (such as penicillin) are those produced naturally (by one microorganism fighting another), whereas nonantibiotic antibacterials (such as sulfonamides and antiseptics) are fully synthetic. However, both classes have the same goal of killing or preventing the growth of microorganisms, and both are included in antimicrobial chemotherapy. "Antibacterials" include antiseptic drugs, antibacterial soaps, and chemical disinfectants; whereas antibiotics are an important class of antibacterials used more specifically in medicine and sometimes in livestock feed Blackwell et al. [2]. Antibiotics are a group of drugs that, as a group, is one of the most widely used drugs in the world. Not surprisingly, the list of antibiotics caused many drug-induced side effects Maliha et al. [3]. The effect of penicillin and streptomycin on the histological structure and function of the liver has been well studied Al-Awar et al. [4,5].

The effects of aminoglycosides and $\beta$-lactams have been reported to be predominantly associated with the formation of excessive reactive oxygen species (ROS), leading to adverse effects on the cellular antioxidant protection system as well as the improvement of the lipid peroxidation (LPO) process Westphal et al. [6-8]. Antibiotics are one of the most commonly used remedies in modern medicine for gold bullets. Continuous expansion of antibiotics reflects their importance and therapeutic role, which is sometimes life-saving. The development of resistance outweighs the effectiveness and is a real threat that continues to expand over time. Several factors contribute to antimicrobial resistance by dividing them into microorganisms and iatrogenes or patients. The irrational use of antibiotics is a major cause of resistance to microbes Morgan et al. [9]. Unlike other Arab countries, Jordan has a higher level of education, but several studies indicate inappropriate prescription and 
abuse of antibiotics in Jordan Al-Azzam et al. [10,11]. Impact of patient confidence, previous experience with antibiotics, pharmaceutical practice, national regulations and incorrect diagnosis and treatment of doctors promote antibiotic resistance Albsoul-Younes et al. [12,13]. Different approaches have been used to positively control antibiotic resistance, namely patient education and patient sensitization Arnold et al. [14].

\section{Uses of Antibiotics}

Antibiotics are used for the purpose of therapeutic options for either treating or preventing bacterial infections, and sometimes against protozoan infections Jones et al. [15]. If an infection is suspected, and the involved pathogen is not identified, then an empirical therapy is initiated which involves the use of a broad spectrum of antibiotics based on the signs and symptoms shown and is started until the laboratory results that can last for several days Leekha et al. [16]. If the responsible pathogenic micro-organism is already known or identified, then the final therapy can be started. This usually involves the use of narrow spectrum antibiotics. The choice of antibiotic also depends on the cost. Identification is very important as it can reduce the cost and toxicity of antibiotic therapy and the possibility of antimicrobial resistance Leekha et al. [16]. Antibiotics can be administered without complicated acute appendicitis to avoid surgery Minutolo et al. [17]. Antibiotics can be given as a preventive measure and are usually restricted to groups at risk, such as people with weakened immune systems (especially HIV pneumonia), people taking immunosuppressive drugs, cancer patients, and patients after surgery Jones et al. [15]. Their use in surgical procedures helps prevent incision infection. They play an important role in dental prophylactic antibiotics if their use can prevent bacteremia and further infectious endocarditis. Antibiotics are used to prevent infectious neutropenia, which is particularly cancer-related Bow et a. $[18,19]$.

\section{Classification of Antibiotics}

The classification of antibiotics depends on their mechanism of action, chemical structure, or spectrum of activity Calderon et al. [20]. Antibiotics can target the bacterial cell wall (penicillins and cephalosporins) or the cell membrane (polymyxins), or interfere with essential bacterial enzymes (rifamycins, lipiarmycins, quinolones, and sulfonamides). Other antibiotics can target protein synthesis inhibitors (macrolides, lincosamides, and tetracyclines) with bacteriostatic activity Finberg et al. [21].

\section{Antimicrobial Resistance}

It has become a common phenomenon for bacteria to resist antibiotics. The developed resistance may reflect evolutionary processes that occur during antibiotic therapy.
However, the antibiotic of choice may target bacteria that have the capability to tolerate high levels of antibiotics. This may lead to enhanced growth of resistant bacteria Levy [22]. It has been shown that well known antibiotics including penicillin and erythromycin that have a high potential against many bacterial species and strains, have become less effective because of increased resistance of many bacterial strains Carol [23]. The term "superbugs" has been used to describe the state of antibacterial-resistant strains that contribute to the developing of previously well controlled diseases. An illustrating example is development of bacterial strains that induce tuberculosis which are resistant to previously effective antibacterial treatments. According to this context, it has been estimated that about half a million new cases of multidrug-resistant tuberculosis (MDR-TB) are likely to occur yearly at global level (WHO, 2019).

Infectious diseases are characterized by their ability to significantly affect a human species Moreno et al. [24]. Since penicillin was introduced in 1943, antibiotics have revolutionized their treatment. However, antimicrobials have weaknesses; the organisms for which they are intended almost always have resistance mechanisms Fauci et al. [25]. An event or resistance may occur regardless of the presence of antibacterial agents. However, it is an effect on this drug that provides the necessary breeding pressure against the spread of resistant pathogens. Anti-antibiotic resistance is a growing global public health problem that could exceed decades of progress in reducing morbidity and mortality associated with infectious diseases. The emergence of antibiotic-resistant bacteria outside drug discovery threatens to put an end to the age of unprecedented achievements in modern medicine Perry et al. [26]. The World Health Organization Global Plan of Action on antibiotic resistance (2010) identified five strategic goals:

a. Raising awareness and understanding;
antimicrobials,

b. Strengthening knowledge through monitoring and research,

c. Reducing the frequency of infections,

d. Optimization of the use of antimicrobials, and

e. In order to ensure sustainable investment in the fight against antimicrobial resistance, all should strive to reduce the burden associated with it Moreno et al. [24].

The Conservative Center for Disease Control and Prevention estimates that at least 23,000 people are died every year in the United States due to infection with antibiotic resisting microorganism Arias et al. [27]. Moreover, the overall economic burden of antibiotic resistance was estimated at only direct costs of $€ 1.5$ billion (2007) in Europe 
and $\$ 55$ billion (2000) in the US. In low- and middle-income countries, the use of antibiotics is increasing with hospital admission and the spread of hospital infections. This burden is likely to lead to longer duration of illness and higher mortality in patients with resistant infections, increased treatment costs for resistant infections, and inability to intervene based on effective antibiotics to prevent infection Laxminarayan et al. [28]. In the US, $50.9 \%$ of pathogens causing surgical infections, and $26.8 \%$ of pathogens causing chemotherapy after infection are resistant to standard prophylactic antibiotics in the US. In addition, 30\% of this reduction could result in 120,000 additional infections and surgical site infections after chemotherapy a year and 6300 infections related to infection Tellinat et al. [29].

In hospitals, high antibiotic use, critically ill patients, and a steady influx of patients in the healthcare system have created pathogenic species that contribute to the development of resistance Roca et al. [30]. In the United States, $4 \%$ of hospital patients have been reported to have at least one case of infection. With healthcare, pneumonia and surgical infections are the most common, followed by gastrointestinal infections Moreno et al. [24]. Strategies to successfully combat bacterial resistance in hospitals include monitoring antibiotic use and demonstrating human and animal resistance; Guidelines for the use of antibiotics in humans and animals; standardized measures for infection control and appropriate personnel, and antibiotic maintenance programs in hospitals and other health care facilities Laxminarayan et al. [24,28,31,32]. Monitoring of bacterial resistance programs generates important information that promotes and manages management activities [33-36]. The latter can reduce the undesirable effects of antimicrobial use by reducing the consumption of antibiotics by $20-40 \%$, the frequency of healthcareassociated infections, the length of stay in the hospital and the spread of bacterial resistance Moreno et al. [24].

\section{Conclusion}

The present study confirmed the importance of antibiotic uses and the aspects associated with their use such as antimicrobial resistance, health and economic impacts.

\section{References}

1. Giguere S (2006) Antimicrobial drug action and interaction: An introduction, in Giguere S, Prescott JF, Baggot JD, Walker `RD, Dowling PM, (Eds.), Antimicrobial Therapy in Veterinary Medicine, ( $4^{\text {th }} \mathrm{edn}$.), Blackwell, Ames, IA, p. 3-9.

2. Blackwell PA, Kay P, Boxall ABA (2007) The dissipation and transport of veterinary antibiotics in a sandy loam soil, Chemosphere 67(2): 292299.

3. Maliha SS, Shahed MJ, Janker MN, Abasi KW, Nigm Rahman AE (2009) Clinical and experimental evidences in antibiotics side effects and toxicity associate with overdose and long-term of use. Pharmacol Assoc J 6(3): 23-31.
4. Akande T, Balogun ST, Gabriel O (2012) The effects of penicillin streptomycin on liver aminotransferases, alkaline phosphatase and total serum protein in rabbits (Orcytolagusconiculus). J Appl Pharm Sci 2: 3235.

5. Al Awar MS, AL Shaibani EA, Salih EM, Al Eryanim MA (2013) The protective effect of nabk honey against pathological effects of penicillin and streptomycin on histological structure and functions of guinea pigs liver. J Appl Pharm Sci 3 (4 Suppl1): S1-S6.

6. Goldstein LI, Ishak KG (1999) Hepatic injury associated with penicillin therapy. Arch Pathol 98: 114-117.

7. Sha SH, Schacht J (1999) Stimulation of free radical formation by aminoglycoside antibiotics. Hear Res 128(1-2): 112-118.

8. Westphal JF, Vetter D, Brogard JM (1994) Hepatic side effects of antibiotics. J Antimicrob Chemother 33(3): 387-401.

9. Morgan D, Okeke I, Laxminarayan R, Weisenberg S (2011) Nonprescription antimicrobial use worldwide: a systematic review. Lancet Infect Dis 11(9): 692-701.

10. Al Azzam S, Al Husein B, Alzoubi F, Masadeh M, Al Horani M (2007) Selfmedication with antibiotics in Jordanian population. Int J Occup Med Environ Health 20(4): 373-380.

11. Sawair F, Baqain Z, Abu Karaky A, Abu Eid (2009) Assessment of selfmedication of antibiotics in Jordanian population. Med Princ Pract 18(1): 5-21.

12. Albsoul Younes A, Wazaify M, Yousef AM, Tahaineh L (2010) Abuse and Misuse of Prescription and Nonprescription Drugs Sold in Community Pharmacies in Jordan. Subst Use Misuse 45(9): 1319-1329.

13. Al Momany N, Al Bakri A, Makahleh Z, Wazaify MM (2009) Adherence to International Antimicrobial Prophylaxis in Cardiac Surgery: A Jordanian Study Demonstrates Need for Quality Improvement. J Manag Care Pharm 15(3): 262-271.

14. Arnold S, Straus S (2005) Interventions to improve antibiotic prescribing practices in ambulatory care. Cochrane Database Syst Rev 4: CD003539.

15. Jones, Bartlett (2011) Antibiotics simplified (2 ${ }^{\text {nd }}$ edn.), p. 15-17.

16. Leekha S, Terrell CL, Edson RS (2011) General principles of antimicrobial therapy. Mayo Clinic proceedings 86(2): 156-167.

17. Minutolo V, Licciardello A, Di Stefano B, Arena M, Arena G, Antonacci $\mathrm{V}$ (2014) Outcomes and cost analysis of laparoscopic versus open appendectomy for treatment of acute appendicitis: 4-years experience in a district hospital. BMC Surg 14: 14.

18. Eric J Bow, D Bacteriol (2013) Infection in Neutropenic Patients with Cancer. Critical care clinics 29(3): 411-444.

19. Flowers CR, Seidenfeld J, Bow EJ, Karten C, Gleason C, et al. (2013) Antimicrobial prophylaxis and outpatient management of fever and neutropenia in adults treated for malignancy: American Society of Clinical Oncology clinical practice guideline. J Clin Oncol 31(6): 794-810.

20. Calderon CB, Sabundayo BP (2007) Antimicrobial Classifications: Drugs for Bugs. ( $1^{\text {st }}$ Edn.). In Schwalbe R, Steele-Moore L, Goodwin AC. Antimicrobial Susceptibility Testing Protocols. CRC Press. Taylor \& Frances group. ISBN 978-0-8247-4100-6.

21. Finberg RW, Moellering RC, Tally FP, Craig WA, Pankey GA, et al. (2004) The importance of bactericidal drugs: future directions in infectious disease. Clinical Infectious Diseases 39(9): 1314-1320.

22. Levy SB (1994) Balancing the drug-resistance equation. Trends in Microbiology 2(10): 341-342.

23. Pearson, Carol (2007) Antibiotic Resistance Fast-Growing Problem Worldwide. Voice of America.

24. Moreno J, Conte E, Tribaldos, et al (2018) Antibiotic resistance profiles in Panama: Trends from 2007 to 2013. Pharm Pharmacol Int J 6(5): 350355. 
25. Fauci AS, Morens DM (2012) The perpetual challenge of infectious diseases. N Engl J Med 366(5): 454-461.

26. Perry J, Waglechner N, Wright G (2016). The Prehistory of antibiotic resistance. Cold Spring Harb Prespect Med 6(6): a025197.

27. Arias C, Murray B (2015) A New antibiotic and the Evolution of Resistance. N Engl J Med 372(12): 1168-1170.

28. Laxminarayan R, Duse A, Wattal C, Anita KM Zaidi, Nithima Sumpradit, et al. (2013) Antibiotic resistance-The need for global solutions. Lancet Infect Dis 13(12): 1057-1098.

29. Tellinat A, Gandra S, Barter D, Morgan DJ, Laxminarayan R (2015) Potential burden of antibiotic resistance on surgery and cancer chemotherapy antibiotic prophylaxis in the USA: a literature review and modelling study. Lancet Infect Dis 15(12): 1429-1437.

30. Roca I, Akova M, Baquero F, Carlet J, Cavaleri M, et al (2015) The global threat of antimicrobial resistance: science for intervention. New Microbes New Infect 6: 22-29.

\section{ISSN: 2574-1241}

DOI: 10.26717/BJSTR.2019.16.002802

Khalid Ababneh. Biomed J Sci \& Tech Res

This work is licensed under Creative Commons Attribution 4.0 License

Submission Link: https://biomedres.us/submit-manuscript.php
31. Lee JH, Park KS, Karim AM, Chang-Ro Lee, Sang Hee Lee (2016) How to minimize antibiotic resistance. The Lancet 16(4): 17-18.

32. Ponce de Leon Rosales S, Arredondo Hernandez R, Lopez Vidal Y (2015) Resistance to antibiotic: A serious global problem. Gac Med Mex 151(5): 632-639.

33. (2010) Global Action Plan on Antimicrobial Resistance. World Health Organization, Geneva, Switzerland, p. 28.

34. (2018) Metronidazole, pp. 443-481.

35. (2019) Antibiotics are used to treat or prevent some types of bacterial infection. They work by killing bacteria or preventing them from reproducing and spreading. But they don't work for everything. When it comes to antibiotics, take your doctor's advice.

36. (2009) Health ministers to accelerate efforts against drug-resistant TB.

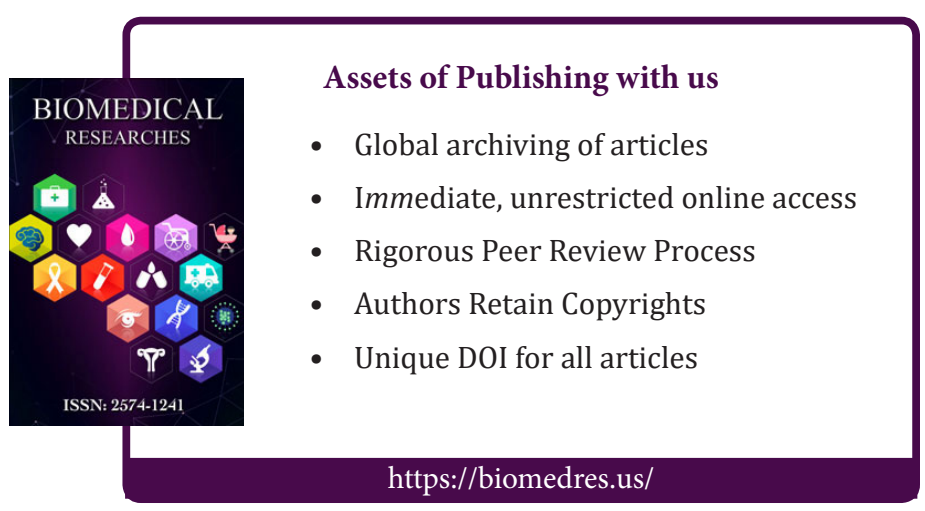

